\title{
Modelos Teóricos em Psicossomática Psicanalítica: Uma Revisão
}

\author{
Maíra Bittar Galdi ${ }^{1}$ \\ Faculdade de Ciências da Universidade Estadual Paulista Júlio de Mesquita Filho, \\ Bauru, SP, Brasil \\ Érico Bruno Viana Campos \\ Departamento de Psicologia da Universidade Estadual Paulista Júlio de Mesquita Filho, \\ Bauru, SP, Brasil
}

\begin{abstract}
Resumo
Este artigo é um estudo teórico da literatura psicanalítica sobre o tema da psicossomática que tem por objetivo revisar os modelos de abordagem desse fenômeno buscando a compreensão de suas diferenças e similitudes em termos de fundamentação teórica. Os resultados apontam para duas maneiras distintas de ver as doenças psicossomáticas, ligadas a duas tradições em psicanálise. Na vertente francesa, ligada mais ou menos diretamente à perspectiva lacaniana, cujas principais referências foram Jacques Alain-Miller e Pierre Marty, o fenômeno não constitui um deslocamento representacional, mas sim uma falha nos processos de simbolização. Em uma segunda vertente, que congrega a Escola Psicossomática de Chicago até autores franceses não lacanianos, cujas principais referências foram Joyce McDougall e Christophe Dejours, o fenômeno psicossomático é compreendido em uma linha divergente, relacionando a formação do sintoma a conflitos inconscientes que são simbolizados na doença, mas em uma forma de simbolização mais precária em relação ao modelo da histeria. Apesar das divergências, entende-se que há conciliação quanto aos princípios na direção do tratamento, que consiste em definir um sentido para o sintoma, não por meio do resgate de uma fantasia inconsciente como no modelo clássico da histeria, e sim construindo um sentido onde não havia encadeamento histórico-narrativo.
\end{abstract}

Palavras-chave: Psicanálise, psicossomática, somatização, simbolização.

\section{Theoretical Models in Psychosomatic Psychoanalysis: A Review}

\begin{abstract}
This article is a theoretical study of the psychoanalytic literature on the subject of psychosomatic that aims to review the approach models this phenomenon seeking to understand their differences and similarities in terms of theoretical basis. The results point to two different ways of looking at psychosomatic illnesses. In the French side, linked more or less directly to the Lacan perspective, the main references were Jacques-Alain Miller and Pierre Marty, the phenomenon is not a representational shift, but a failure in symbolization processes. In a second aspect, which brings together from the Psychosomatic School of Chicago to French authors not Lacanian, the main references were Joyce McDougall and Christophe Dejours, the psychosomatic phenomenon is understood in a divergent line, relating the formation of the
\end{abstract}

Endereço para correspondência: Rua Christiano Pagani, 8-51, Apto 53a , Bairro Jardim Auri Verde, Bauru, SP, Brasil 17047-144. Fone: (14) 3204-8979/(14)98111-6015. E-mail: mah.bg@hotmail.com

Este trabalho é fruto da pesquisa de iniciação científica "Fundamentos da Psicossomática Psicanalítica", desenvolvida pela primeira autora e orientada pelo segundo autor no programa de Iniciação sem Bolsa da Universidade Estadual Paulista "Júlio de Mesquita Filho" - UNESP (PIBIC-ISB). 
symptom the unconscious conflicts. They are symbolized in the disease, but in a more precarious form of symbolization from the model of hysteria. Despite the differences, it is understood that no compromise on the principles towards the treatment, which is to define a meaning for the symptom, not by the rescue of an unconscious fantasy as in the classic model of hysteria, but building a sense where there was no historical narrative thread.

Keywords: Psychoanalysis, psychosomatic, somatization, symbolization.

\section{Modelos Teóricos en Psicosomática Psicoanalítica: Una Revisión}

\section{Resumen}

Este artículo es un estudio teórico de la literatura psicoanalítica sobre el tema de psicosomática que tiene como objetivo revisar los modelos de aproximación a este fenómeno que tratan de comprender sus diferencias y similitudes. Los resultados apuntan a dos formas diferentes: En el lado francés, vinculado más o menos directamente a la perspectiva Lacaniana, las referencias principales fueron Jacques-Alain Miller y Pierre Marty, el fenómeno no es un cambio de representación, pero un fallo en los procesos de simbolización. En un segundo aspecto, que reúne en la Escuela Psicosomática de Chicago a los autores franceses no Lacanianos, las referencias principales fueron Joyce McDougall y Christophe Dejours, el fenómeno psicosomático se entiende en una línea divergente, relativa a la formación del síntoma los conflictos inconscientes Ellos están simbolizadas en la enfermedad, pero en una forma más precaria del modelo de la histeria. A pesar de las diferencias, se entiende que hay compromiso en los principios hacia el tratamiento, que consiste en definir un significado para el síntoma, no por el rescate de una fantasía inconsciente como en el modelo clásico de la histeria, pero la construcción de un sentido en que no había ningún hilo narrativo histórico.

Palabras clave: Psicoanálisis, psicosomática, somatización, simbolización.

No século XIX, o surgimento dos casos de histeria fez emergir questões capciosas para o projeto da medicina científica e naturalista. Em um contexto histórico onde a razão e o culto à consciência imperavam, os sintomas como paralisias e inibições que não tinham seu correspondente orgânico intrigavam e se colocavam como um desafio para a época, o que permitiu que outras ciências, que não se encerravam na lógica positivista, lançassem as diretrizes de um arcabouço teórico que pudesse dar conta dessa realidade. Nesse sentido, no contexto dos estudos sobre a histeria de Freud e Breuer (1895), o conceito de Inconsciente vai sendo delineado, bem como as técnicas e os métodos que permitem sua investigação, levando à composição de uma nova ciência: a Psicanálise, constituída por um objeto e um método específicos.

Inicialmente investigado através da técnica da hipnose, o Inconsciente foi descoberto como possuindo suas próprias leis de funcionamento que fogem totalmente à consciência, e é por meio dessas leis que Freud desvendou o mecanismo conversivo que havia por trás dos sintomas histéricos. A conversão foi descrita por Freud como um mecanismo inconsciente, presente na matriz clínica da neurose histérica, em que a pulsão ligada a uma ideia é recalcada e convertida em representantes ideativos do próprio corpo. Mas não se trata, aqui, do corpo biológico, e sim do corpo erógeno, dotado de uma anatomia imaginária, que subverte o corpo real, de tal forma que a ordem erógena se constitui como um duplo da ordem biológica a partir da superfície corporal (Leclaire, 1979/1992). O corpo erógeno é aquele que tem, em sua anatomia imaginária, fantasias sexuais específicas que, de alguma maneira, estão interligadas a um órgão correspondente. É, portanto, um corpo desejante, que supera o determinismo biológico: os órgãos não são utilizados somente para satisfazer as necessidades de sobrevivência, como ocorre com os animais, 
mas também satisfazem, expressam e evocam desejos, e é nisso que o homem se diferencia dos animais: ele tem pulsões e não instintos.

Porém, o corpo erógeno não nasce com o ser humano. Para que ele exista e se desenvolva é necessário um outro alguém que o invista sexualmente, ou seja, que deseje, que imagine uma história, que direcione seu olhar para o corpo. Todo esse processo não é simples - vai desde a etapa do narcisismo primário até as etapas posteriores de construção da sexualidade - e sempre, por alguns infortúnios da vida a que todos estão sujeitos, pode ser interrompido, se desorganizar ou regredir para fases anteriores do desenvolvimento. O corpo erógeno também é passível de falhas. $O$ investimento libidinal nele nunca é uniforme: pode-se investir demais em uma região - como na histeria - ou falhar em outra como se supõe que aconteça no fenômeno psicossomático - e essa questão também é fruto de algumas divergências teóricas no campo.

Sendo assim, a psicanálise, em sua descoberta e na investigação do mecanismo de conversão abalou os pilares do racionalismo cartesiano, rompendo definitivamente com a medicina com a introdução do conceito de corpo erógeno, inaugurando uma nova forma de saber: o Inconsciente. É por essa razão que falar em Psicossomática em Psicanálise revela-se uma questão espinhosa. Como teorizar sobre aquilo que ela própria negou, em sua origem, como campo de saber? Ao mesmo tempo em que essa negação do corpo real a definiu em sua ruptura com o positivismo, agora a divide e se coloca enquanto desafio contemporâneo - visto que, atualmente, o mal estar psíquico tem suas mais variadas expressões no corpo biológico.

Mas o que é a Psicossomática? Também essa questão se apresenta de forma difusa. Mesmo na medicina vemos divergências quanto a sua definição. Uma vertente da medicina de influência hipocrática tem na psicossomática uma filosofia, uma visão de homem e de mundo no qual corpo e mente não se dividem. Tudo abrange Psiquê e Soma, ou seja, tanto a saúde como a doença fazem parte de processos mentais e somáticos que são unificados e que formam a totalidade que é o ser humano. Por outro lado, outra vertente considera apenas alguns tipos de doenças sendo psicossomáticas, o que retoma as discussões dualistas - já que, sob essa perspectiva, existem doenças que englobam a psique e outras não (Mello \& Burd, 2010). Com relação a esta última vertente, vemos que mesmo com a ruptura com a medicina na qual a Psicanálise surgiu, em alguns aspectos elas ainda se aproximam, tal como a descrição e categorização dessas doenças correlacionando-as com conflitos inconscientes específicos realizada pela Escola de Chicago (Casetto, 2006).

Dessa forma, o limite tênue entre processos fisiológicos e psicológicos é novamente problematizado com a reinserção da psicanálise nas questões do real do corpo. Dessa investigação surge a noção de que, para além das fantasias que são simbolizadas em uma anatomia imaginária, o corpo biológico também pode servir de escoadouro para fantasias não nomeadas e até mesmo de suporte para simbolizações precárias, ou seja, modalidades mais arcaicas de representação do que aquelas consideradas no modelo neurótico clássico. No entanto, as diferentes vertentes das escolas psicanalíticas se dividem quanto à natureza específica desse fenômeno, trazendo convergências e divergências entre si.

Os principais pontos de discussão residem nas elucidações sobre uma entidade clínica presente ou não nos casos dos fenômenos psicossomáticos, a inexistência ou não de uma articulação simbólica na doença e, por fim, a dificuldade com que a psicanálise se encontra, até os dias atuais, de descrever metapsicologicamente esse tipo de fenômeno. Para tanto, serão estudados alguns dos principais teóricos envolvidos nessa problemática: Franz Alexander - líder da Escola Psicossomática de Chicago, Pierre Marty - do Instituto de Psicossomática de Paris (IPSO), Jacques Alain Miller, Joyce McDougall e Christophe Dejours.

\section{Caracterização}

A psicanálise, no geral, considera doença psicossomática todo fenômeno que não se restringe apenas às explicações biológicas médicas, mas que insiste em aparecer, permanecer e que 
também não se enquadra nos sintomas de neuroses clássicas. É um diagnóstico, portanto, por exclusão, e também por isso que surgiram tantos rumores - principalmente de autores próximos a Lacan - se não estaríamos diante de uma nova matriz clínica que não as clássicas neuroses, psicoses e perversões.

Desse grupo de pensadores, Pierre Marty é o mais representativo dessa linha de pensamento. Líder do Instituto de Psicossomática de Paris (IPSO), sua obra se divide em, basicamente, três períodos. No primeiro, mais biologicista, descrevendo o processo de desorganização psicossomática como resultado de uma tensão entre os Instintos de Vida e os Instintos de Morte. Estes teriam uma fonte somática, e a morte não era o fim, mas sim a consequência desse desequilíbrio biológico, diferentemente do que afirmavam os lacanianos e os outros membros do instituto. Sendo assim, as desorganizações atingiam, primeiro, as áreas do corpo erógeno, com o intuito de proteger o corpo contra desorganizações maiores, até que o psiquismo se reestabeleça. Caso a desorganização seja mais grave, o corpo essencialmente biológico também é atingido, podendo causar a morte. $\mathrm{O}$ psiquismo, segundo ele, é evolutivamente mais recente que os pontos somáticos (Casetto, 2006), e, por isso mesmo, o primeiro a ser atingido na decorrência de um trauma.

A segunda parte de seu trabalho foi voltada para uma construção teórica mais psicanalítica, com a introdução dos conceitos chaves de sua obra: mentalização, pensamento operatório e depressão essencial. Para ele, uma baixa capacidade de mentalização, ou seja, de metabolização de traumas através dos símbolos, leva o sujeito à chamada depressão essencial. A depressão essencial é caracterizada por uma depressão sem objeto específico, muito diferente do luto, por exemplo, que geralmente tem o componente da perda do objeto com seu desinvestimento libidinal conseguinte. A desvitalização psíquica da depressão essencial não tem seu correspondente no investimento em pensamentos suicidas ou depreciadores - como ocorre nos casos de depressão clássica. Há um desinvestimento maciço em tudo, não se tratando tanto de tristeza, mas sim de apatia, aumentando a frequência de doenças e acidentes psicossomáticos.

Na última fase de sua obra, Marty de preocupou em formular uma classificação nosológica da psicossomática, segundo categorias diferentes com relação à capacidade de mentalização. Elas seriam mais inferiores em relação à capacidade de simbolização que os neuróticos, psicóticos e perversos: "Inicialmente chamou-as de neurose de comportamento e neuroses de caráter, e depois subdividiu as últimas em neurose mal mentalizada, neurose de mentalização incerta e neuroses bem mentalizadas" (Casetto, 2006, p. 12).

Talvez por uma influência de sua fase biologicista, Vieira (1997) aponta que, para Marty, a doença psicossomática não tem o papel que a pulsão de morte tem para Freud, pois seu objetivo final não é a morte, pelo contrário: pode ser uma defesa que, impedindo desorganizações mais severas, opera para assegurar a integridade do organismo. Pouco a pouco, os conceitos de mentalização e pensamento operatório foram se sobrepujando em relação a outros aspectos teóricos de sua jornada - como os conceitos de depressão essencial - e até mesmo sobre a fase mais voltada para a descrição biologicistas. Sua contribuição teórica é bastante marcada pelo destaque na carência de simbolizações do psiquismo nos pacientes psicossomáticos, e esse aspecto será retomado, aprofundado e problematizado por todos os outros autores posteriores.

Outra grande vertente na Psicossomática Psicanalítica foi a Escola de Chicago, liderada por Franz Alexander. Ela limita as doenças psicossomáticas em sete perturbações clássicas: asma brônquica, úlcera gástrica, artrite reumatoide, retocolite ulcerativa, dermatoses, tireotoxicoses e hipertensão. Diferentemente do que ocorre com a histeria, Volich (2000) aponta que Alexander não considera o fenômeno como uma solução de compromisso, ou seja, o fenômeno não é uma tentativa de cura e solução do conflito psíquico. Para ele, Alexander desenvolveu a noção de constelação psicodinâmica especifica para tentar explicar a origem da doença. Nela, propõe que certos conflitos internos estão diretamente relacionados a reações emocionais especí- 
ficas, cada uma correspondendo a cada conflito, embora a relação estabelecida entre as emoções e as doenças não seja causal.

Essas duas grandes escolas desempenharam um papel muito importante, tanto na prática como na construção de uma teoria psicanalítica sobre as doenças psicossomáticas. Foram elas que construíram um corpo teórico no qual os psicanalistas posteriores se apoiaram, modificaram e problematizaram essas construções, contribuindo para o avanço dos conhecimentos nesse assunto relativamente recente. Em discussões posteriores, encontramos importantes referenciais teóricos em Jacques-Alain Miller, Joyce McDougall e Christophe Dejours.

Até então, as construções teóricas sobre a psicossomática psicanalítica não consideravam a possibilidade do desenvolvimento de doenças psicossomáticas em outras estruturas subjetivas que não as que funcionam no modo operatório. Sobre esse ponto, Miller (1987) chega a considerar a existência do fenômeno em outras estruturas subjetivas, porém, não deixa de teorizar sobre uma possível subjetivação própria do psicossomático.

Segundo esse autor, o psicossomático pode ser uma estruturação muito primitiva, próxima da psicose e da debilidade mental. Ele deixa muito evidente a relação de oposição do fenômeno psicossomático ao sintoma histérico. A diferença que se dá, precisamente, reside no fato de que, diferentemente do que ocorre no fenômeno, o sintoma conversivo não incide no corpo real (biológico), mas sim no corpo erógeno (imaginário). O sintoma, segundo ele, reside no campo das neuroses, obedecendo a uma estrutura de linguagem subjacente, que opera através dos processos da metáfora e do deslocamento, sendo, portanto, carregado de significados inconscientes, o que, segundo ele, não ocorre nos fenômenos psicossomáticos.

Certamente, é crucial, essencial, distinguir o sintoma, especialmente o histérico, e o fenômeno psicossomático, precisamente nisso que esta relação ao Outro é constitutiva do sintoma histérico, o que de nenhum modo é o caso do fenômeno psicossomático, se ele existe. (Miller, 1987, p. 89)
O fenômeno não está inserido em uma estrutura de linguagem, mas também não está completamente fora dela, caracterizando-se por um fenômeno limite. Isso quer dizer que, embora haja alguns aspectos da linguagem presente, seus mecanismos de formação ainda não são claros para ele, por pertencerem a uma simbolização muito mais arcaica, fora do campo das neuroses. Embora Miller reconhecesse que o fenômeno não esteja restrito somente a um tipo de personalidade, isso não obteve muito destaque em sua concepção teórica, que foi inteiramente desenvolvida sob a noção de uma estruturação psíquica específica que, por apresentar dificuldades nos processos simbólicos, apresentava a somatização como consequência.

Não houve maiores esclarecimentos sobre o que pode levar a uma saída psicossomática, psicótica ou autista, visto que, para Miller (1987), essas estruturas são muito próximas. Além disso, não fica explicito o porquê de uma falha na simbolização em alguma área circunscrita não pode ter o retorno em delírio ou uma passagem ao ato. O que é percebido é que esses fenômenos apresentam muita semelhança com as psicoses, tanto em seus mecanismos, quanto na estrutura familiar. A carência de simbolização, o fato de não ter sido idealizado e representado por um significante pelos pais, são comuns a essas duas estruturas, resultando em uma lacuna nas repostas que poderiam existir sobre a escolha por uma saída ou outra.

Joyce McDougall, de certa forma, supera essas elucidações teóricas, ao reconhecer que não existe uma estrutura subjetiva própria dos fenômenos psicossomáticos. Além disso, em seu livro Teatros do Corpo (McDougall, 1996) a autora aborda a somatização como todo tipo de passagem ao ato, que inclui o uso de substâncias, o aumento da vulnerabilidade aos acidentes corporais e as falhas do sistema imunológico.

Para denominar esse mecanismo muito frequentes nos somatizadores, no qual o afeto não é pensado, McDougall (1996) criou o termo desafetação. $\mathrm{O}$ afeto é um conceito limite, assim como é o de pulsão, estando entre o somático e o psíquico. O estado de desafetação consiste, basicamente, em uma incapacidade de refletir so- 
bre as emoções vividas intensamente. $\mathrm{O}$ fato de essas pessoas vivenciarem emoções fortes não é tão prejudicado, embora haja constantemente uma tentativa de fuga dessas vivências. Mas a capacidade de nomeação, diferenciação e reflexão sobre seus estados afetivos mais intensos é quase nula. Além da projeção dos afetos, a desafetação consiste em um mecanismo que também projeta a representação para o exterior. Nesse ponto, McDougall afirma um novo destino para os afetos, o repúdio para fora do ego, a acrescentar nos três já existentes (deslocamento, conversão, transformação em angústia). Ao afeto que foi ejetado em sua parte psíquica, resta somente se exprimir através de sua dimensão orgânica, como na primeira infância, reduzindo, assim, a mensagem do psiquismo a um funcionamento não verbal.

À primeira vista, há algumas semelhanças com o pensamento operatório descrito pelo Instituto de Psicossomática de Paris, principalmente com relação a ruptura do sistema consciente/ inconsciente, resultando em um funcionamento psíquico pragmático e muito concreto. Porém, no caso do pensamento operatório, há também uma incapacidade de vivenciar essas emoções, o que pode ocorrer na desafetação, mas não constitui necessariamente uma regra.

Há certa semelhança entre os mecanismos de desafetação, foraclusão e projeção, visto que são mecanismos brutais de extirpação de afetos e representações. As diferenças residem no fato de que na projeção, o conteúdo de uma pulsão é suprimida e deformada, retornando ao consciente como uma representação ligada a um objeto externo. Na desafetação é o afeto que é repudiado, sem retorno sobre um objeto externo ou alucinatório. Seu destino é ser escoado pela via somática. Na projeção, portanto, a representação não é totalmente lançada para fora do psiquismo, já que algumas representações permanecem no objeto externo. $\mathrm{Na}$ desafetação toda cadeia representativa é excluída, sem retorno.

Quanto às angústias dominantes no quadro das doenças psicossomáticas, essas estão muito mais próximas das angústias psicóticas do que das histéricas. Basicamente, se referem á perda da identidade individual, sexual e à perda dos li- mites corporais. Esses medos primitivos deixam em qualquer indivíduo vestígios psíquicos que estão ligados aos temores de todo bebê, que são, em grande parte, resolvidos na fase fálico-edipiana. Mas quando não resolvidas e a angústia psicótica domina o quadro clínico, não estamos mais diante de uma problemática histérica, embora os pacientes somatizadores também não sejam psicóticos. "Talvez estejamos na posição de perguntar-nos se muitas organizações neuróticas, histéricas e obsessivas não são, no fundo, construídas a partir de um núcleo psicótico" (McDougall, 1996, p. 21).

Muito se fala, nos textos revisados, sobre a etiologia das doenças psicossomáticas. Joyce McDougall, nesse ponto, não difere muito com relação aos outros autores. A organização familiar agressiva e sua consequente pobreza mental que abrem caminho para uma doença são fatores citados em praticamente todas as obras. Mas pouco é dito sobre os mecanismos metapsicológicos existentes nela. Apesar de a autora ter criado um novo conceito, o da desafetação, pouco se entende sobre sua especificidade. A desafetação - se definindo pelo repúdio para fora do ego é um mecanismo semelhante ao dos psicóticos, que utilizam a foraclusão - termo utilizado pela escola lacaniana - ou a projeção - termo próprio da escola inglesa. A autora ressalta a dimensão afetiva que é repudiada, talvez essa seja a diferença com relação á foraclusão, que ejeta somente a representação, sem a carga afetiva. Pouco é dito, também, sobre a formação da doença a partir desse mecanismo, somente uma passagem breve que afirma que quando a dimensão psíquica do afeto é repudiada, a dimensão orgânica se expressa. Além disso, ela afirma que a desafetação não tem um retorno em forma de delírio, como tem a foraclusão ou a projeção. Se, na desafetação, toda cadeia representativa é destruída, como explicar seu retorno no corpo sob uma forma precária de simbolização? Também perdura, aqui, a questão do porque o retorno não se dar em forma de delírio.

Sobre os elementos que poderiam ser utilizados na construção de um sentido, pouco também é dito. Sabemos que ele não se configura em uma simbolização como ocorre na histeria, pois 
é muito mais arcaico, mas não sabemos do que dispomos para desvendá-lo. Sobre esse ponto, o próximo autor acrescenta contribuições teóricas muito importantes, se atendo na importância da dimensão agressiva não representada presente na somatização, através de um mecanismo semelhante, que ele denominou de clivagem do inconsciente. Além disso, o autor procura explicar e oferecer uma solução para as indagações que não foram respondidas pelos autores anteriores, sobre a questão do elemento que diferiria entre uma saída psicossomática ou psicótica, baseado na observação das diferenças entre os pais dos psicóticos e os dos somatizadores. Porém, antes, é necessário explicar alguns conceitos básicos de sua teoria, como sua própria definição de doenças psicossomáticas, a noção de subversão libidinal e de construção do corpo erógeno.

Dejours (1991) ressalta que, em sua concepção, se existe um dualismo presente é aquele entre o corpo erógeno e o corpo fisiológico, não a partir de uma relação de oposição, mas sim de superação do segundo sobre o primeiro. No entanto, a construção do corpo erógeno nunca é completamente bem-sucedida, podendo ocorrer falhas na convocação de algum órgão, ou também do desapoio da pulsão de alguma área, a partir de algum traumatismo ocorrido na vida do sujeito. É assim que a questão da escolha de órgão é tratada: as áreas corporais que não foram suficientemente subvertidas são facilmente atingidas nas somatizações.

Apesar da semelhança com a teoria de Lacan, no que se refere à questão da escolha de órgão, há divergências entre as opiniões com relação à origem da pulsão. Para Dejours (1991), a pulsão provém de uma fonte biológica, inata, enquanto que, para Lacan - e para os autores pós-lacanianos - a pulsão provém da linguagem, mais especificamente de significantes que a mãe insere no bebê em seus primeiros meses de vida.

Após essa abordagem inicial sobre os preceitos básicos que orientam sua teoria, algumas questões mais específicas sobre a problemática das somatizações serão abordadas, como a terceira tópica - ou tópica da clivagem - e a dimensão agressiva não representada como a problemática central das doenças psicossomáticas.
A agressividade que não pôde ser representada ocorre a partir da clivagem do inconsciente em inconsciente primário/secundário. $\mathrm{O}$ autor retoma a hipótese freudiana, a de que o inconsciente também é constituído por traços filogenéticos, considerando o inconsciente primário como sede dos traços herdados. Já o inconsciente secundário, por sua vez, é aquele ligado às representações simbólicas. A pulsão de morte, portanto, impedida de ser representada pelo pré-consciente, opera de forma destrutiva no corpo orgânico, através das doenças psicossomáticas. Dessa forma, o sujeito permanece desconhecido de sua própria violência. Buscando preservar a aparente normalidade no vínculo social, essa violência não é atuada, mas sim dirigida contra o próprio sujeito, que desfere um golpe inconsciente contra o próprio corpo em forma de somatização. Dejours (1991) sugere que a própria somatização pode ser simbolizadora de algum aspecto perdido da história dessas pessoas. Essa é mais uma inovação no campo da psicossomática psicanalítica, pois, até agora, nenhum autor havia citado a possibilidade de ver a somatização como um elemento facilitador que faz desenrolar o processo da análise. A violência do analisando não é expressa concretamente. De forma mais sutil, ela é percebida mais no âmbito negativo: faltam palavras que signifiquem suas experiências emocionais em seu discurso, bem como expressões corporais e faciais mais espontâneas e autênticas. Outro mecanismo de defesa é proposto na tentativa de explicar o processo de somatização: o de repressão dos afetos agressivos. Esse mecanismo procura eliminar os afetos desde sua fonte, que, segundo o autor, é biológica. Ele se diferencia do mecanismo do recalcamento porque este opera somente sobre as representações, em nível pré-consciente/inconsciente, impedindo que as representações recalcadas ultrapassem a barreira do inconsciente até o pré-consciente. $\mathrm{O}$ consciente perde totalmente o contato com o conteúdo recalcado, enquanto que, na repressão, a representação aparece, por vezes, intacta ao consciente, podendo sumir logo em seguida. Diferentemente do recalcamento, a repressão opera a nível consciente/pré-consciente. Ela se opõe mais especificamente contra o 
desenvolvimento do afeto e não de elementos representacionais. Portanto, vemos que o recalque opera mais a nível psíquico das representações, enquanto que a repressão em um nível mais afetivo e corporal.

A partir disso, o autor declara que interpretar um sintoma psicossomático se trata, efetivamente, de interpretar a pulsão de morte. Esse é um processo que procura vincular a pulsão de morte com a pulsão de vida, esvaziando seu potencial traumático. As somatizações simbolizadoras devem ser identificadas, segundo o autor, eliminando a hipótese de depressão essencial. Portanto, ele considera toda a proposição teórica do Instituto de Paris, mas faz uma diferenciação entre os tipos de somatização: as desorganizações progressivas são diferentes das somatizações simbolizadoras. Nas primeiras, a violência é parcialmente inibida, ao passo que na segunda, é reprimida maciçamente. O que é observado, então, é que algumas somatizações abrem caminho para revelar um conflito ou uma parte da história do sujeito que permanecia oculta, a qual ele não entrava em contato, por ser uma história traumática. A partir disso, observava-se que o decurso da análise, antes aparentemente congelado, começava a se desenrolar, o que permite também evocar a noção de "facilitação psicossomática" (Dejours, 1991, p. 28).

As semelhanças encontradas com as relações mãe/bebê dos psicóticos também são muitas. Dejours (1991) ressalta que a diferença reside no fato de que os pais do psicótico procuram desviar os pensamentos dos filhos, criando um pensamento alienado, não original. Os pais do psicossomático, entretanto, procuram destruir qualquer tipo de pensamento que ele possa vir a ter, principalmente os de cunho sexual. Mas não é somente nesse aspecto que, na teoria de Dejours, essas psicopatologias passam a ser próximas: ele propõe uma hipótese de que as doenças mentais, em especial as psicoses, sejam agregadas às doenças psicossomáticas. Nesse ponto, o autor leva em conta as descobertas das neurociências, segundo a qual essas funções dependem da montagem hereditária do sistema nervoso. Dessa forma, é pensado também que, no caso das psicoses, o desapoio da pulsão, ao invés de se dar nas áreas viscerais - como ocorre com as doenças psicossomáticas - se dá no cérebro, comprometendo as áreas referentes à cognição e à linguagem, que são as funções mais comprometidas nos psicóticos.

Dejours (1991) e McDougall (1996) já oferecem um maior avanço na técnica, no sentido de que um trabalho interpretativo é arriscado, sendo, por isso, mais operativo, embora Dejours (1991) também considere a relevância da terapêutica de Marty, procedimento do qual denominou pára-excitação. A escolha entre os dois procedimentos terapêuticos, segundo ele, depende da disposição do analisando de enfrentar sua verdade. Do ponto de vista clínico, Dejours (1991) oferece uma inovação, ao constatar que as somatizações ocorrem também em estruturas neuróticas de personalidade. No que se refere à técnica, o autor também insere uma nova proposição, a de que as somatizações devem ser interpretadas através de seus conteúdos agressivos e mortíferos. Para ele, portanto, um sentido subjacente à doença pode ser desvendado, procurando ligar a dimensão traumática da pulsão de morte à libido.

\section{Discussão}

Apesar de haver algumas divergências teóricas, como já constatado, as opiniões acerca dos fenômenos psicossomáticos seguem certo padrão, no que se refere às características dos pacientes que apresentam esse tipo de problemática. Há consenso com relação à incapacidade de simbolização presente nesses quadros clínicos, embora as teorias tenham seguido um movimento de, no início, considerar a falta de simbolização como sendo estruturante nesses casos, se desdobrando para a noção de que a essa falta não é estruturante, mas sim circunscrita a alguns pontos do discurso. Também perdura, de maneira geral, a concordância com relação à falta de afetividade, as referências à ausência de vida onírica e fantasmática, além de uma extrema concretude de pensamentos, concomitantemente a um estilo de vida extremamente pragmático. Todos esses fatores são elencados e denominados, pelos membros do Instituto de Psicossomá- 
tica de Paris, de pensamento operatório, na Escola Psicossomática de Chicago, de Alexitimia, e Joyce McDougall utiliza o mecanismo defensivo da desafetação para designar esses elementos característicos. Dejours não chega a criar um novo conceito para denominar essas características da personalidade, sendo que a ênfase de sua teoria recai na hipótese da clivagem do inconsciente e na dimensão da agressividade não representada. Contudo, as incursões teóricas de autores pós Lacanianos, como Miller, apontam para a consideração de outros mecanismos defensivos que possam coexistir com o de foraclusão, dando a ideia de que a foraclusão do Nome-do-Pai não instaura a lógica geral de simbolização nos casos psicossomáticos, como ocorre nos psicóticos, mas sim é um mecanismo circunscrito, que pode coexistir com o recalque, a denegação, etc. No entanto, ainda assim um perfil do paciente psicossomático é mantido e este se encontra muito próximo do perfil do psicótico, o que parece permanecer uma opinião contraditória com o restante da teoria, ou, ainda, que faltam mais elementos teóricos para se pensar na ocorrência das somatizações no âmbito das subjetividades bem mentalizadas. As ideias de McDougall caminham para a aproximação da psicossomática com a histeria, concordando com a dimensão simbólica, mas mais arcaica do que o sintoma, que o fenômeno oferece.

A aproximação da psicossomática com a psicose também é realizada por Dejours, mas com a diferença de que, nesse caso, há a proposição de tratar as doenças conhecidas como "mentais" em nossos dias atuais como doenças psicossomáticas também, onde haveria o desapoio da pulsão, e, dessa forma, a vulnerabilidade para a pulsão de morte. Isso explicaria o porquê dos psicóticos e autistas serem prejudicados nas funções de linguagem e cognição, enquanto que seu sistema imunológico permanece extremamente forte. Dejours oferece uma pista para uma melhor compreensão acerca das diferenças encontradas na saída psicótica e na psicossomática. Apesar das semelhanças elencadas entre ambas, vemos que existe a diferença com relação aos destinos dos pensamentos dos pacientes na primeira infância. Também é notável o papel im- portante exercido pelos pais na libidinização das áreas corporais, que, segundo ele, pode ser decisivo entre uma eclosão psicótica ou uma eclosão psicossomática.

Com relação às discussões sobre a atribuição de um sentido simbólico sobre a doença e sobre os mecanismos metapsicológicos envolvidos nela, alguns avanços também foram alcançados no desenrolar das teorias, como a construção de um sentido sobre a doença, o que também oferece um avanço na prática clínica - que se mostra, dessa maneira, um pouco mais operativa. Além disso, algumas descobertas importantes sobre a dimensão agressiva presente nessa problemática possibilitou com que fossem criadas tentativas mais esclarecedoras da metapsicologia envolvida no caso das somatizações, fato que é verificado na proposição da terceira tópica de Dejours.

Sendo assim, apesar de, no início, a relação entre a incapacidade de simbolização e a eclosão de uma doença corporal ter sido abordada de forma mais direta, progressivamente foi observado a presença de mais elementos metapsicológicos envolvidos nas somatizações - como o mecanismo de desafetação e de clivagem das imagos, de McDougall, e da tópica da clivagem e da repressão da agressividade, de Dejours - que, de certa forma, problematizaram uma questão que aparentemente se apresentava de forma um pouco mais simplificada e direta.

Com relação ao caminho percorrido pelas discussões sobre o sentido do fenômeno psicossomático, vemos que as discussões iniciais clássicas da psicanálise, realizadas pelos membros do Instituto de Psicossomática de Paris, caminharam para questionar se o fenômeno chegaria a abarcar a estrutura de linguagem. Apesar dessa opinião também parecer ser a posição tomada por Lacan, Miller não conclui a questão, oscilando entre as posições de afirmação da inexistência de qualquer elemento simbólico contido nela ou admitindo a possibilidade de alguma inserção na linguagem, o que abriria a possibilidade para classificá-lo como um fenômeno de borda, ou seja, que está nos limites do universo simbólico.

Entre os autores franceses, é apenas com a introdução das ideias de Dejours que uma construção de sentido sobre a lesão é proposta, mas, 
diferentemente do sintoma histérico, que é interpretado através das fantasias eróticas recalcadas do sujeito, o fenômeno psicossomático deve ser interpretado a partir das pulsões agressivas reprimidas. No entanto, Dejours não é considerado um autor estritamente pós-lacaniano, permanecendo desconhecidas as posições tomadas por estes na atualidade. Já McDougall realiza uma aproximação com as ideias de Dejours, reforçando que a somatização se trata de uma história oculta da vida do sujeito, que foi impossibilitada de ser representada para ele próprio e para alguém. Por isso a necessidade de (re)construção dessa história perdida, que daria sentido à somatização. Ainda assim, apesar de haver esses avanços tanto no âmbito teórico quanto no clínico, as simbolizações dos fenômenos psicossomáticos são muito mais arcaicas que as de um sintoma histérico, permanecendo uma certa dificuldade em seu desvendamento.

Sobre o movimento percorrido das construções teóricas acerca de um sentido, Casetto (2006) observa:

. . . colocando-se estas diferenças em perspectiva no tempo, detecta-se o que parece ser um certo movimento (dialético): a somatização transita de um modelo mais estritamente conversivo para a sua negação, e em seguida para um terceiro estado em que se apresenta como um horizonte de significações ainda irrealizado. (p. 17)

Apesar desses avanços no percurso trilhado, uma teoria que explique todos os mecanismos metapsicológicos por trás das somatizações ainda não foi alcançada. Talvez essa dificuldade advenha da própria problemática - que se revela em casos difíceis pela extrema neutralização com que esses pacientes se apresentam na clínica - mas, ainda mais do que esse fato, sobrevém a constatação de que a doença psicossomática é um fenômeno que abarca tanto a dimensão biológica quanto psíquica, sendo necessário, por isso, rever nossas concepções acerca da natureza da mente e do corpo, bem como o modo de interação que se dá entre essas duas instâncias. Isso ficou muito claro na obra de Dejours a partir de seu conceito de subversão libidinal, mas embora a psicanálise tenha inovado com o con- ceito limite de pulsão, ela se apegou muito mais a teorizar sobre mecanismos psíquicos, carecendo de explicações quando se depara com um fenômeno tanto biológico quanto psíquico. Essa dificuldade já foi apontada por Birman (2001) que considera que esse fato, muito mais do que ser traduzido por uma insuficiência teórica, foi estabelecido por um pacto entre a psicanálise e a medicina, operando uma separação entre as questões do psiquismo, que deve ser investigadas pela primeira, e as questões do corpo, restritas somente à segunda. Essa cisão ocorreu na emergência da psicanálise e seu questionamento das ciências positivistas, e deve ser revista nos dias atuais, através de uma demanda da própria realidade psicossomática que vem aumentando nas clínicas.

Por fim, há a necessidade, também, da consideração de outros aspectos constitutivos do fenômeno psicossomático que não apenas os genéticos, inconscientes e aqueles construídos a partir das relações primitivas com os pais. Isso se refere a uma maior busca por respostas no âmbito da vida social dos sujeitos, pois, se as doenças psicossomáticas vêm aumentando nos dias atuais, não haveria, na nossa sociedade contemporânea, elementos presentes nos quais estariam contribuindo para um aumento do mal-estar psíquico expresso através do corpo?

A discussão se amplia para uma observação do próprio funcionamento de nossa sociedade atual, na qual as relações de trabalho refletiriam apenas um aspecto de seu funcionamento. Os valores difundidos pelos meios sociais como o individualismo, o consumismo e a competição estariam contribuindo para a construção de identidades fragmentadas, despersonalizadas:

A questão seria: será que a sociedade capitalista contemporânea, com seus valores supremos atrelados ao consumo, não estaria produzindo uma espécie de despersonalização que viria à reboque do fenômeno de massificação? Vivemos em uma cultura cujos imperativos favorecem o aparecimento da doença normótica? Fica aqui uma hipótese mais ampla, a ser trabalhada em outro momento, de que o estilo de vida fragmentário que nos oferece a sociedade contemporânea, 
afinal, em nada favorece aquilo que se pode chamar de uma boa mentalização. (Ferraz, 1997, p. 172)

Esse é um debate interessante e necessário para a psicanálise, que oferece a possibilidade de pensar a construção da subjetividade para além daquela estabelecida pelas relações familiares da primeira infância, buscando integrar, também, aspectos atuais da vida do sujeito - tanto relacionais como o sofrimento psíquico no trabalho - caminhando, de modo mais amplo, para discussões do próprio contexto histórico e social na qual está inserido, o que é um fator importante, visto que estabelece maiores relações com o meio externo e relacional, sem deixar de lado as dinâmicas intrapsíquicas.

\section{Considerações Finais}

As discussões em psicossomática percorreram um caminho que mantém certo padrão de teorização, principalmente no que se refere aos sintomas e funcionamento psíquico, que nas descrições se caracterizam como um funcionamento concreto, pragmático, carente de símbolos e vida onírica. Como vimos, em Miller e Pierre Marty a ideia de uma estrutura de personalidade do psicossomático é mais forte. As primeiras incursões de Lacan não deixam muito claras se ele concluiu sua opinião com relação a isso, já que ele considerava que as doenças psicossomáticas estariam no limite do analisável, por ser considerado um fenômeno da ordem do real do corpo. Talvez esse seja o motivo pelo qual ele não incluiu o psicossomático em suas classificações de estruturas psíquicas. Ainda assim, fica implícita a questão de um mecanismo estruturante de forclusão do Nome-do-Pai, que aproximaria o psicossomático do psicótico e do autista. Entretanto, Miller afirma que o fenômeno psicossomático é um fenômeno limite, porque adere em alguns aspectos - ainda desconhecidos - à estrutura de linguagem. Seria o caso de considerar, já a partir de Lacan, a possibilidade em se pensar no psicossomático como um arranjo limítrofe, visto que não se chegou a alcançar um funcionamento neurótico, mas também foi ultrapassada a organização psicótica? Pois é visto que a sim- bolização não é ausente, como é nos psicóticos, mas também é de ordem mais arcaica do que ocorre com os neuróticos.

Apesar de Dejours e McDougall terem reconhecido o fenômeno para além desse tipo de funcionamento psíquico, suas teorizações ainda transitam nesse âmbito, com McDougall discorrendo sobre a desafetação e Dejours sobre a repressão da agressividade. Portanto, os mecanismos que estariam por trás das somatizações em psiquismos com funcionamento mais neurótico ainda permanecem carente de explicações e elucidações metapsicológicas.

Com relação às dificuldades encontradas no processo de pesquisa, estas residem na própria dificuldade inerente ao tema, que pouco é explorado pelos autores psicanalíticos, e, quando o fazem, realizam uma teoria voltada para o negativo: a incapacidade simbólica desse tipo de subjetivação é citada em todos os autores revisados, e, apesar de reconhecerem que as doenças psicossomáticas não estão restritas somente ao modo operatório, os elementos também carecem para se pensar essa problemática fora desse âmbito postulado por Pierre Marty. Além disso, os textos apresentados sobre esse tema muitas vezes são concisos e pouco didáticos em sua explanação. Nesse sentido, houve muita dificuldade na carência de maiores explicações de alguns conceitos e até mesmo de exemplos concretos para um melhor entendimento. Talvez no fundo a psicanálise ainda seja um pouco leiga quando se trata do assunto da psicossomática e por isso as obras revisadas caminham no mesmo sentido de mecanismos gerais de explicação e descrição e carecem um pouco da contribuição de novos elementos para se pensar nessa problemática.

Nossas impressões caminham para a opinião de que as doenças psicossomáticas são muito mais frequentes e muito menos restritas do que sugerem os autores tradicionais da psicossomática psicanalítica. Talvez uma pista para identificar a ocorrência de uma doença psicossomática seja se ater em fatos desencadeadores da lesão na vida do sujeito, o que diferiria de outras doenças que sua etiologia possa ser atribuída a causas mais orgânicas e menos psíquicas. Acreditamos ainda que as discussões acerca da de- 
limitação das doenças psicossomáticas das não psicossomáticas deva ser revista, pois também é notório que a ocorrência de alguns traumas (luto, separação) desencadeie doenças orgânicas e estas deveriam ser consideradas mais psicossomáticas do que aquelas que não comportam um acontecimento emocional desencadeador. Por fim, reiteramos sobre a importância de estabelecer um diálogo com os modos de subjetivação que vêm sendo produzidos em nossa sociedade, pois a própria psicanálise caminha para discussões existentes entre o modo de produção capitalista atual e o adoecimento no trabalho.

\section{Referências}

Birman, J. (2001). Corpos e formas de subjetivação em Psicanálise. Estados Gerais de Psicanálise. Recuperado em http://egp.dreamhosters. com/encontros/mundial_rj/download/3_Birman_38020903_port.pdf

Casetto, S. J. (2006). Sobre a importância de adoecer: Uma visão em perspectiva da psicossomática psicanalítica no século XX. Psychê, 10 (17), 1-22. Recuperado em http://pepsic.bvsalud. org/scielo.php?script=sci_arttext\&pid $=$ S1415$-11382006000100008 \& \operatorname{lng}=\mathrm{es} \& n r m=$ iso

Dejours, C. (1991). Repressão e subversão em psicossomática: Pesquisas psicanaliticas sobre o corpo. Rio de Janeiro, RJ: Jorge Zahar.
Ferraz, F. C. (1997). O mal-estar no trabalho. In R. M. Volich, Psicossoma: Psicossomática Psicanalítica II. São Paulo, SP: Casa do Psicólogo.

Leclaire, S. (1992) O corpo erógeno: Uma introdução à teoria do complexo de Édipo. São Paulo, SP: Escuta. (Original publicado em 1979)

McDougall, J. (1996). Teatros do corpo: $O$ Psicossoma em psicanálise (2. ed.). São Paulo, SP: Martins Fontes.

Mello, J., Filho, \& Burd, M. (Eds.). (2010). Psicossomática hoje (2. ed.). Porto Alegre, RS: Artmed.

Miller, J.-A. (1987). Algumas reflexões sobre o fenômeno psicossomático. In R. Wartel, Psicossomática e Psicanálise (pp. 87-97). Rio de Janeiro, RJ: Jorge Zahar.

Vieira, W. de C. (1997). A psicossomática de Pierre Marty. In F. C. Ferraz \& M. R. Volich, Psicossoma: Psicossomática Psicanalítica (pp. 15-22). São Paulo, SP: Casa do Psicólogo.

Volich, R. M. (2000). Psicossomática (2. ed.). São Paulo, SP: Casa do Psicólogo. 